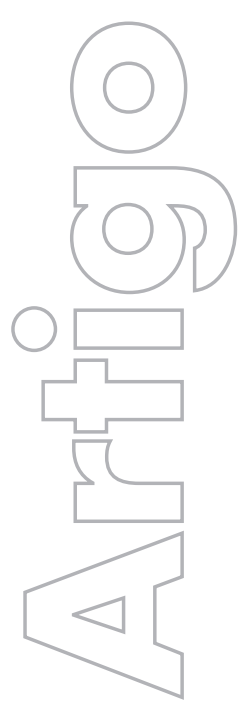

revista

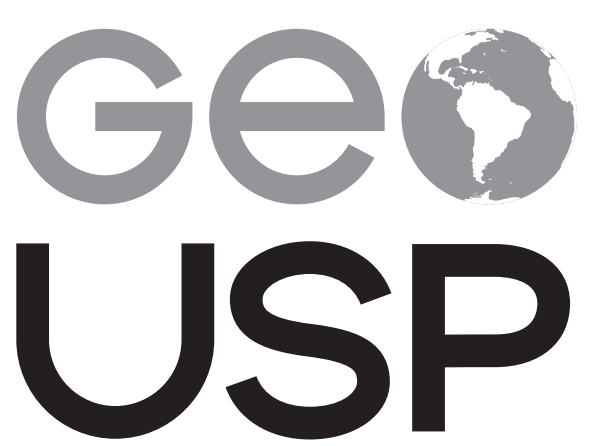

espaço e tempo

Volume $22 \cdot n^{\circ} 1(2018)$

ISSN 2179-0892

\section{Caracterização da dinâmica dos ventos em Curitiba-PR}

\author{
Francisco Jablinski Castelhano \\ UFPR \\ Wilson Flavio Feltrim Roseghini \\ UFPR
}

p. $227-240$

Como citar este artigo:

CASTELHANO, F. J.; ROSEGHINI, W. F. F. Caracterização da dinâmica dos ventos em Curitiba-PR. Geousp Espaço e Tempo (Online), v. 22, n. 1, p. 227-240, mês. 2018. ISSN 2179-0892.

Disponível em: <http://www.revistas.usp.br/geousp/article/ view/123088> . doi: http://dx.doi.org/10.11606/issn.2179-0892. geousp.2018.123088.

\section{(c) $(1) \Theta$}

Este artigo está licenciado sob a Creative Commons Attribution 4.0 License. 


\title{
Caracterização da dinâmica dos ventos em Curitiba-PR
}

\section{Resumo}

Este trabalho visa caracterizar a dinâmica dos ventos na cidade de Curitiba, capital do estado do Paraná, região Sul do Brasil. Para tanto, colheram-se dados de direção e velocidade dos ventos na estação meteorológica do Simepar no período de 2004 a 2015, totalizando 12 anos de dados em escala horária. A análise se baseou na geração de boxplots apontando a oscilação da velocidade dos ventos em escala mensal e horária e na criação de gráficos em rosa dos ventos indicando as direções predominantes, novamente em escala horária e mensal. Concluiu-se que os ventos predominantes em Curitiba provêm dos setores leste e nordeste o ano todo e que, ao longo do dia, se alternam.

Palavras-chave: Velocidade do vento. Direção do vento. Curitiba. Oscilação mensal. Oscilação horária.

\section{Characterization of wind dynamics in Curitiba-PR}

\begin{abstract}
The present paper aims to characterize the dynamics of the winds in the city of Curitiba, capital of the state of Paraná, Southern region of Brazil. To do such characterization, Wind direction and Wind speed data were collected at the official meteorological station of Simepar, for the period from 2004 until 2015, an amount of 12 years of hourly data. The analyzes were made upon the generation of boxplots, pointing the oscillation on the Wind speed values at monthly and hourly scale, and the generation of Wind rose graphics revealing the predominant directions in hourly and monthly scales. It was concluded that the winds in Curitiba are predominantly from the sectors East and Northeast during all the year, and during a day, they alternate themselves.
\end{abstract}

Keywords: Wind directions. Wind speed. Curitiba. Monthly oscillation. Daily oscillation.

\section{Introdução}

O deslocamento de ar (horizontal e vertical) gerado por diferença nos valores de densidade do ar gera o elemento do tempo conhecido como vento. Muitos são os fatores que influem em sua direção e velocidade, entre eles o relevo,vegetação, feições urbanas etc. (Danni-Oliveira; Mendonça, 2007). 
A direção e a intensidade dos ventos são dinâmicas, e sua mudança repentina pode ter uma série de consequências positivas ou negativas em função de sua influência direta em diversos fenômenos ligados ao homem, tais como poluição do ar, geração de energia, agricultura e conforto térmico, entre outros.

A título de exemplo, segundo Alonso; Godinho (1992), a pior situação de poluição do ar na cidade de Cubatão, estado de São Paulo, que chegou a ser conhecida como Vale da Morte, estava ligada a ventos a baixas velocidades, impossibilitando a diluição dos poluentes emitidos pelas indústrias petroquímicas da região, em decorrência da presença do anticiclone do Atlântico Sul que atua na região.

A vivacidade dos ventos foi atestada por Munhoz e Garcia (2008) em estudo realizado em Ituverava, interior do estado de São Paulo, ao apontar uma diferença próxima a 40\% na velocidade média dos ventos entre os períodos diurnos e noturnos.

Em estudo semelhante realizado na cidade de Seropédica, estado do Rio de Janeiro, Oliveira Júnior et al. (2013) apontam pouca diferença na direção predominante dos ventos entre os meses de inverno e verão e predominância de ventos a sudeste em ambas as estações.

No mesmo estudo, os autores atestaram mudanças significativas na direção e velocidade dos ventos em escala horária, com valores distintos entre os horários noturnos e diurnos. Segundo eles, durante a madrugada, os ventos mantinham velocidades entre $1 \mathrm{~m} / \mathrm{s}$ e $2 \mathrm{~m} / \mathrm{s}$, com prevalência da direção norte, enquanto à tarde a direção prevalente era sul, com velocidade média entre $3 \mathrm{~m} / \mathrm{s}$ e $4 \mathrm{~m} / \mathrm{s}$.

Partindo dessa ideia e com base nos estudos supracitados, o objetivo deste trabalho é analisar e caracterizar a dinâmica dessa variável no município de Curitiba, capital do Paraná, região Sul do Brasil (Figura 1).

O município situado a uma altitude média de $935 \mathrm{~m}$ tem aproximadamente 1,8 milhões de habitantes (IBGE, 2010). A cidade está no Primeiro Planalto Paranaense, tendo a Serra do Mar a $40 \mathrm{~km}$ a leste e a escarpa devoniana a cerca de $60 \mathrm{~km}$ a oeste.

\section{Figura 1 - Localização do município estudado e sua respectiva estação meteorológica}



fonte: Águas Paraná ([s.d.]). 
Danni-Oliveira e Mendonça (2007) afirmam que o clima de Curitiba se classifica como subtropical úmido com inverno frio, sendo regido principalmente por massas de ar tropical (Atlântica e Continental) e polares (Atlânticas), sendo que no verão é possível observar ainda a atuação da Massa Equatorial Continental.

Para os autores, as características mais marcantes desse tipo de clima são a distribuição pluviométrica regular ao longo do ano, em conjunto com baixas temperaturas no inverno. Aliado a isso, a região de Curitiba tem sua altitude, o que reduz ainda mais as temperaturas. Ressalta-se que, nos meses de inverno, chove menos, mas essa diferença com os outros períodos é considerada baixa, e não se pode caracterizá-lo como uma estação seca (Figura 2).

A Figura 2 ilustra a normal climatológica de temperatura e chuva em Curitiba segundo o Inmet. Observa-se que a cidade tem sua temperatura média mais baixa no mês de julho $\left(12,9^{\circ} \mathrm{C}\right)$, enquanto a mais quente é em fevereiro $\left(20^{\circ} \mathrm{C}\right)$, mostrando uma amplitude média de $7,7{ }^{\circ} \mathrm{C}$ ao longo do ano.

\section{Figura 2 - Normais climatológicas - 1961-1990 \\ P.P $(\mathrm{mm})$ -Temp. Média}

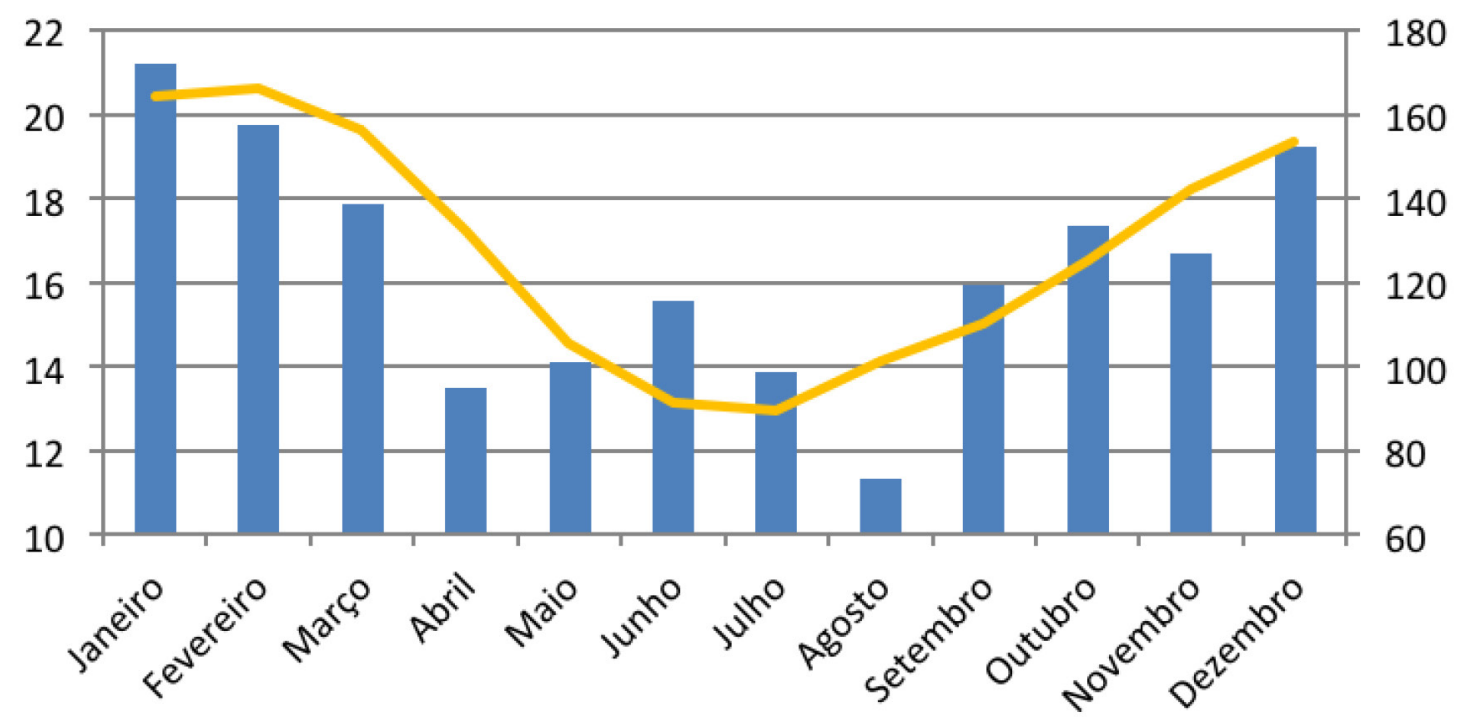

fonte: Inmet ([s.d.]).

As chuvas apresentam padrão geral semelhante ao comportamento das temperaturas: são altas no verão e, conforme se aproxima o inverno, diminuem. Observa-se que isso acontece de março/abril até setembro, quando elas voltam a aumentar. $\bigcirc$ mês menos chuvoso é agosto, com uma precipitação acumulada média de 73,4 mm de chuva, enquanto janeiro é o mais chuvoso, com 171,8 mm (Inmet, [s.d.]).

No que tange o comportamento dos ventos, poucos foram os estudos a este respeito, os quais se destacam estudos do Instituto Agronômico do Paraná (Caviglione et al., 2000) e de Danni-Oliveira (1999).

O estudo de Caviglione et al. (2000) deflagrou as direções predominantes dos ventos em algumas das principais cidades do estado do Paraná e envolveu dados de 1978-1998. A Figura 3 mostra os resultados deste estudo. 
Figura 3 - Carta climática - direção predominante do vento Paraná - 1978-1998

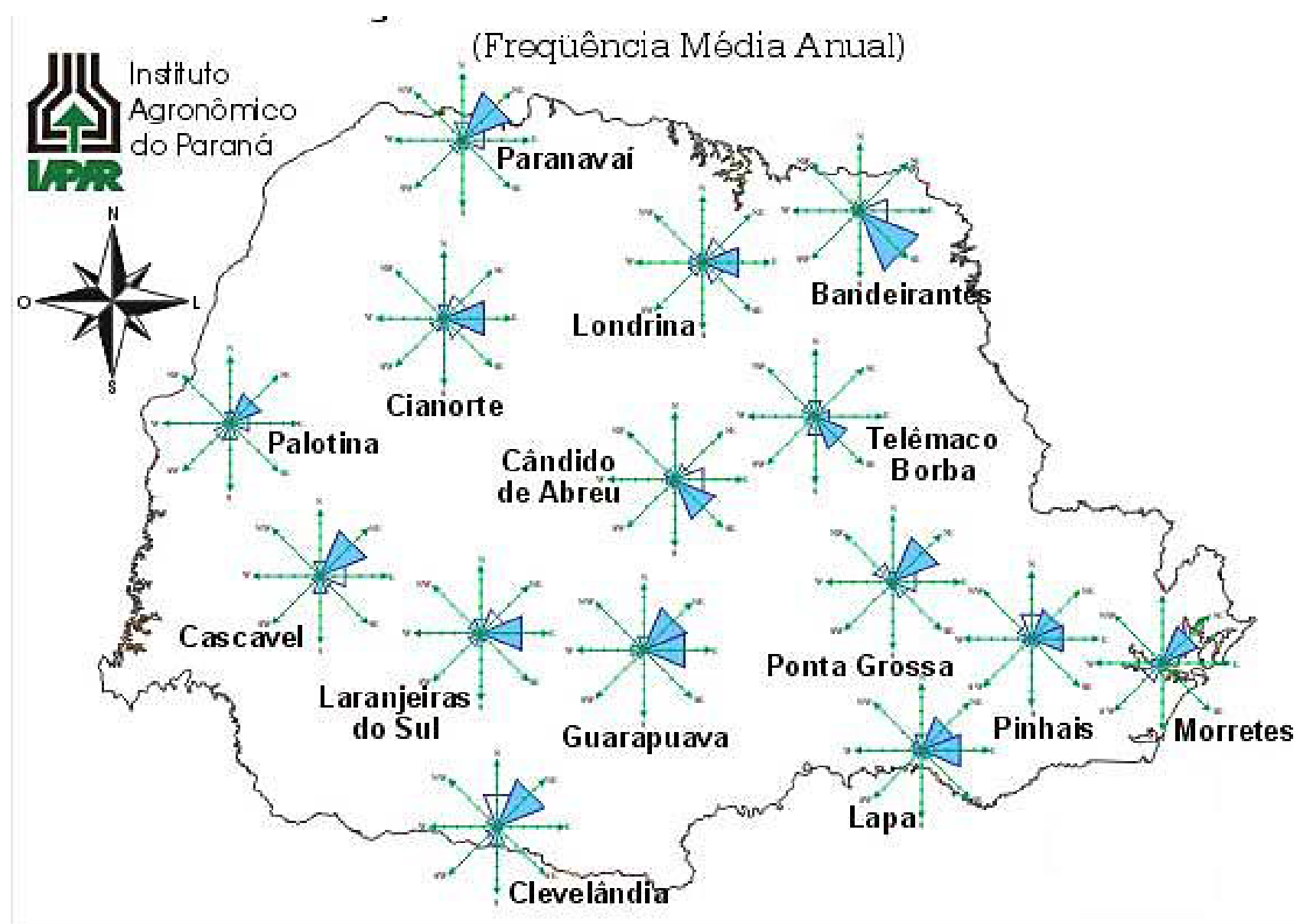

fonte: Caviglione et al. (2000).

Este estudo trouxe dados provindos da estação meteorológica da cidade de Pinhais, cidade limítrofe a Curitiba. Os valores apontam predominância de ventos leste seguidos por nordeste e norte.

Em estudo mais detalhado, realizado apenas na cidade de Curitiba e utilizando dados de 1951-1988, Danni-Oliveira (1999) aponta a predominância dos ventos NE, seguidos por E, SE e NW.

Segundo a autora, de dezembro, janeiro, fevereiro e março, a predominância de ventos no município provém do quadrante leste. Nos outros meses, observam-se uma diminuição dos ventos naquela direção e um aumento nos ventos de nordeste (Figura 4). 


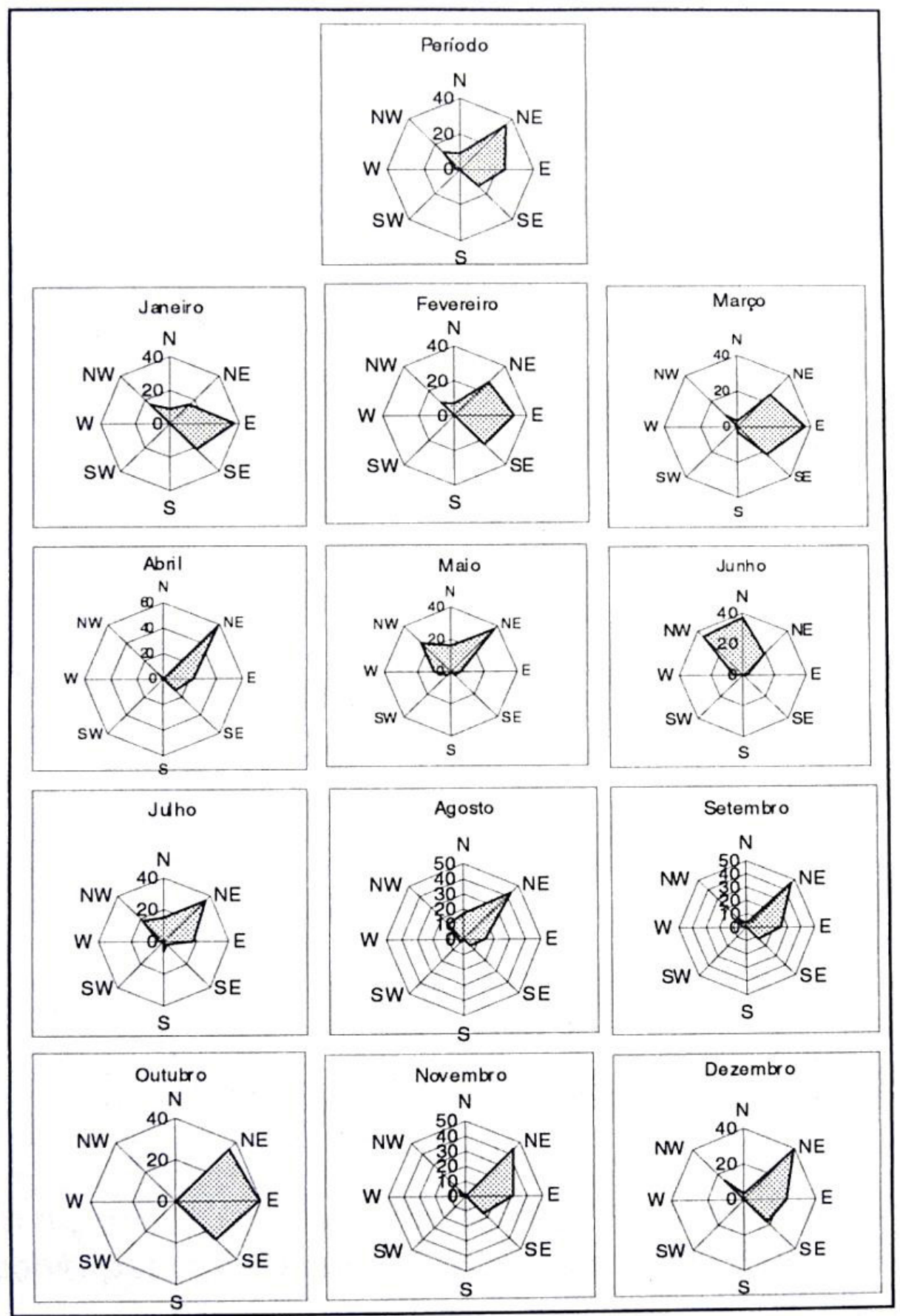

fonte: Danni-Oliveira (1999).

O conhecimento da dinâmica atmosférica regional é fundamental para a caracterização dos ventos na área de estudo, principalmente porque se faz necessária uma articulação entre as diferentes escalas abordadas, permitindo identificar as condições climáticas existentes.

Danni-Oliveira (1999) aponta ainda que o inverno apresenta maior estabilidade atmosférica que as outras estações, devido principalmente à presença ocasional de Massas Polares (com ventos do quadrante sul) intercaladas a atuação predominante da Tropical Atlântica (com ventos do quadrante leste-nordeste), sendo esses sistemas mais estáveis e que geram ventos com velocidade média mais baixa nessa época do ano. 
Nessa dinâmica, as massas de ar na América do Sul já foram estudadas por Monteiro (1973), identificando a característica de cada sistema atmosférico nas escalas espacial e local, como se vê na Figura 5, que, além das condições médias anuais, representa as características da circulação atmosférica regional no verão, com predomínio das massas tropicais úmidas, e no inverno, com diminuição das chuvas, maior incursão da massa polar e queda acentuada da temperatura, principalmente no centro-sul do Brasil.

No caso específico de Curitiba, a dinâmica dos ventos respeita, quase criteriosamente, um ritmo bem marcado da direção onde se origina e do sistema atmosférico atuante: na maior parte do ano, a Massa Tropical Atlântica (Ta) é a principal geradora dos ventos do quadrante leste registrados na área de estudo, proporcional à atuação predominante dessa massa de ar (Danni-Oliveira; Mendonça, 2007).

Com a aproximação de sistemas frontais, o vento muda paulatinamente para o quadrante norte, passando primeiro pelas direções nordeste, norte e depois noroeste, quando permite o aporte de ar quente proveniente das regiões Norte e Centro-Oeste do país, favorecendo o aquecimento pré-frontal.

Durante o verão, essa dinâmica é responsável pelo transporte de umidade da Massa Equatorial Continental Amazônica (Ec), que, conectada ao sistema frontal estacionário e/ou ciclogênese sobre o litoral sudeste do país, em conjunto com os JBN (jatos em baixos níveis), Alta da Bolívia favorecem a formação de Zonas de Convergência de Umidade (ZCOU-ZCAS) (Danni-Oliveira; Mendonça, 2007).

Com a chegada e atuação do sistema frontal, a direção do vento é registrada em diferentes quadrantes: ora de sul, quando da influência da Massa Polar Atlântica ( $\mathrm{Pa}$ ) em sua retaguarda, ora do quadrante norte devido aos ventos quentes e úmidas das massas tropicais e equatoriais.

\section{Figura 5 - Sistemas atmosféricos e massas de ar atuantes na América do Sul(*)}
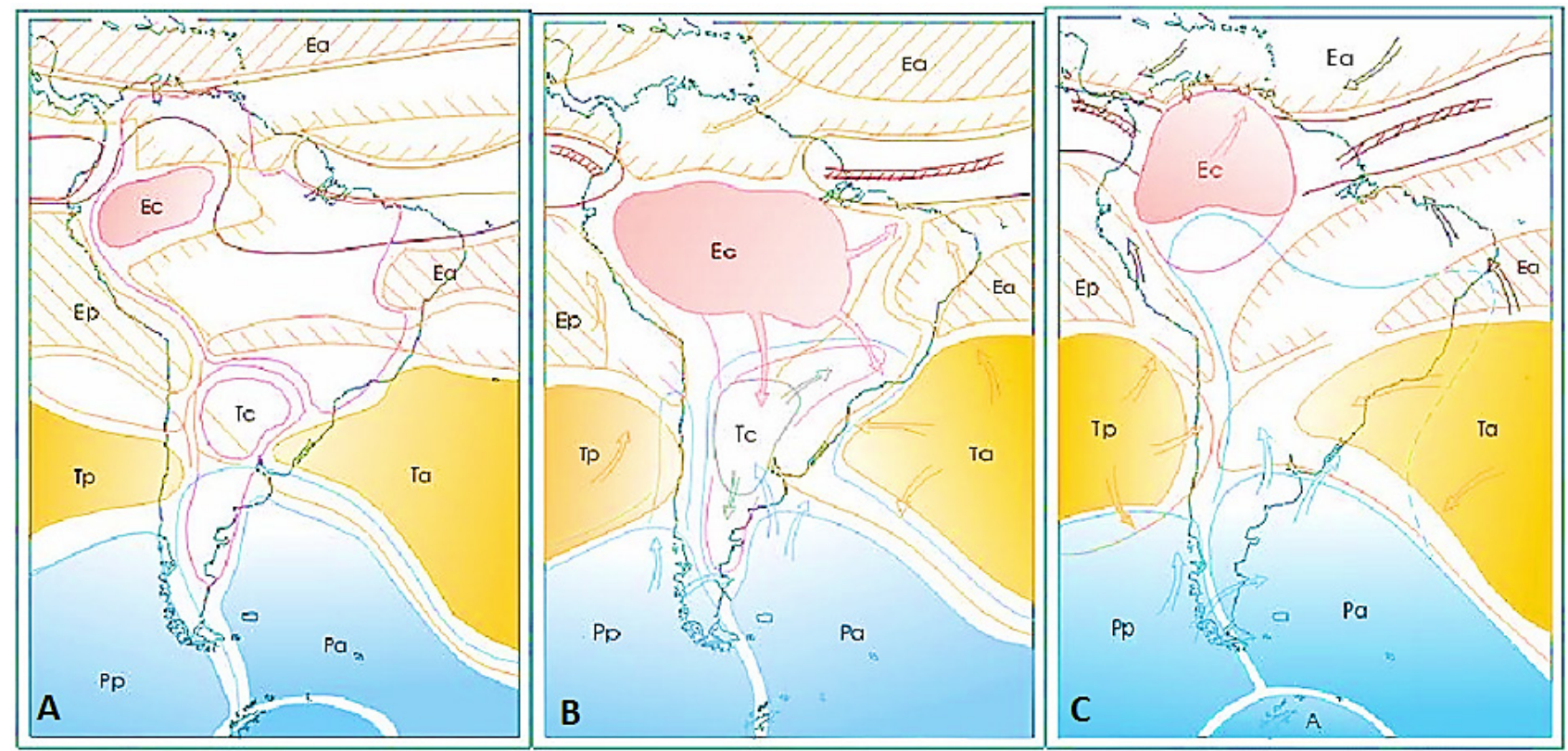

fonte: Monteiro (1973).

(*) A - anual, B - verão, C - inverno. 
Após a passagem do sistema frontal tem-se o avanço do ar polar, fazendo com que os ventos passem a soprar do quadrante sul durante sua atuação, primeiro passando pela direção oeste, depois sudoeste (fase de maior advecção), sul e por fim sudeste, quando o centro da alta desloca-se para o oceano Atlântico.

Devido a latitude subtropical da área em estudo, as massas polares se estabelecem por pouco tempo na região, mesmo durante o inverno, permitindo a rápida tropicalização e o retorno da mTa, garantindo a Massa Tropical Atlântica maior predominância espaço-temporal (Figura 5c), já que tem um caráter semiestacionário no Atlântico Sul, enquanto as massas polares têm o caráter mais transitório, o que explica a pouca frequência de ventos sul mesmo no inverno.

Por fim, com a tropicalização da massa polar e seu avanço para nordeste, voltam os ventos a soprar de leste e toda dinâmica retorna ao ponto inicial, até que outro sistema frontal se aproxime.

\section{Material e métodos}

Para uma análise integral da dinâmica dos ventos em Curitiba foram coletados dados de direção e velocidade em escala horária junto à estação meteorológica do Simepar para o período de 2004 a 2015, totalizando 12 anos de dados. No trabalho de Danni-Oliveira (1999), o período de amostra é menor, mas o fato de os dados serem em escala horária aumentou o detalhamento do presente estudo em relação àquele.

A estação fica na região leste da capital (Figura 1) e colhe dados relativos a ventos a 10 $\mathrm{m}$ de altura, conforme protocolo de instrumentação da WMO.

Os dados de direção do vento providos pelo Simepar estavam organizados por graus de azimute em nove classes: $0^{\circ}, 45^{\circ}, 90^{\circ}, 135^{\circ}, 180^{\circ}, 225^{\circ}, 270^{\circ}, 315^{\circ}$ e $360^{\circ}$, correspondentes aos pontos cardeais e colaterais. As respectivas direções encontram-se explanadas pela figura 6 .

\section{Figura 6 - Direção dos ventos em graus de azimute}

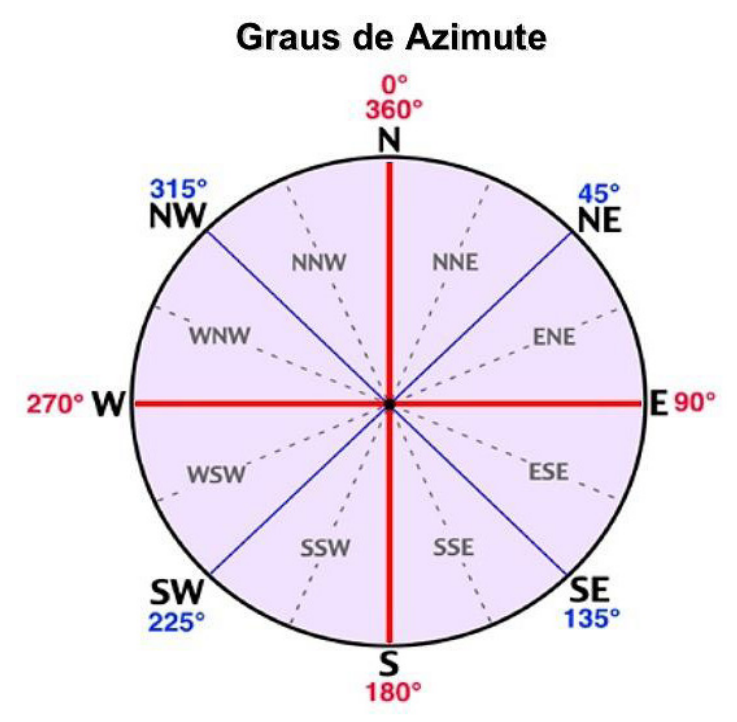

Os dados foram organizados no software Excel, e as análises estatísticas, no software RStudio e no pacote de dados Openair, desenvolvido por Carslaw e Ropkins (2012). 
Os dados gerados possibilitaram a elaboração de gráficos em diferentes escalas temporais, mensal e diária, propiciando uma análise aprofundada para a cidade de Curitiba.

Optou-se por fazer duas análises distintas, a primeira envolvendo apenas a oscilação da velocidade do vento, a fim de descrever a variação mensal e horária da informação nos níveis mensal e horário. Foram gerados boxplots representando a oscilação dos valores registrados nesses 12 anos de dados coletados, conforme método utilizado em Oliveira Júnior et al. (2013).

$\bigcirc$ uso de boxplots permite representar juntos limites superiores e inferiores, primeiro e terceiro quartil e a mediana da série de dados do período, o que simplifica a análise de séries longas, como a adotada aqui. Para melhorar a visualização da oscilação dos valores, optou-se por excluir das plotagens os valores considerados outliers.

Em seguida, foi realizada análise integrada dos dados de velocidade e direção dos ventos através de gráficos no estilo Rosa dos Ventos indicando a frequência da direção e dos valores de velocidade. Esses gráficos apontam em percentual a frequência em cada quadrante e, por escala de cores, a frequência de valores de velocidade do vento.

\section{Resultados e discussão}

A Figura 7 ilustra a oscilação mensal dos valores de velocidade dos ventos em Curitiba. Os meses de abril a julho são aqueles com os valores mais baixos, principalmente porque durante o período vai se estabelecendo a predominância de apenas uma massa de ar na região (mTa), intercalada em alguns períodos com as massas polares. A partir de agosto os valores aumentam até fevereiro, com o retorno das massas Tropical Continental e Equatorial Continental.

\section{Figura 7 - Oscilação média mensal dos valores de velocidade dos ventos (m/s) em Curitiba - 2004-2015}

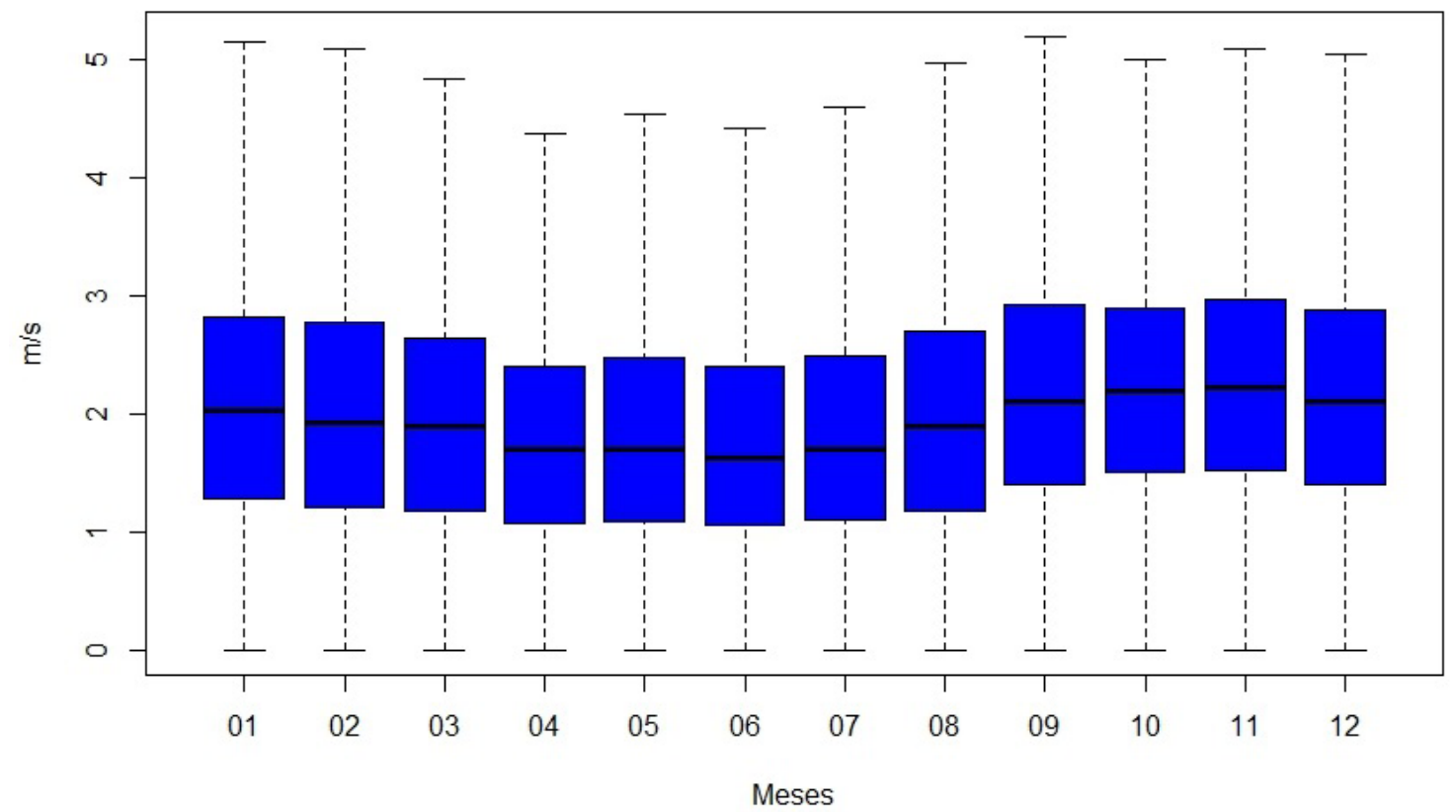

Observou-se que os valores ficaram abaixo de $6 \mathrm{~m} / \mathrm{s}$ em todas as estações, com medianas oscilando entre $1,7 \mathrm{~m} / \mathrm{s}$ e 2,4 m/s. Os limites superiores dos meses com menores valores (abril, maio, junho e julho) ficaram abaixo de $5 \mathrm{~m} / \mathrm{s}$. 
A flutuação dos valores apresentados na Figura 7 segue a lógica temporal de temperatura e chuva (Figura 2), sendo os meses de abril a julho os menos chuvosos e mais frios e também os com ventos de menor velocidade.

Observando a oscilação em escala horária, percebe-se diferença na velocidade média dos ventos registrados ao longo do dia. A figura 8 deflagra dita variação. $\bigcirc$ período da madrugada e início da manhã é aquele com menor velocidade, sendo que às 06 h os registros são mais baixos, tanto de mediana, quanto de limite superior.

A partir das $08 \mathrm{~h}$, percebe-se um incremento gradual da velocidade até as $13 \mathrm{~h}$ e $14 \mathrm{~h}$, a partir de quando, inicia-se uma queda até as 6 da manhã.

No período de maior velocidade, entre $12 \mathrm{~h}$ e $16 \mathrm{~h}$, observaram-se um limite superior próximo a $6 \mathrm{~m} / \mathrm{s}$ e uma mediana em torno de $2,5 \mathrm{~m} / \mathrm{s}$. Por outro lado, nos horários com velocidades mais baixas, entre $04 \mathrm{~h}$ e $07 \mathrm{~h}$, o limite superior oscilou entre $3,7 \mathrm{~m} / \mathrm{s}$ e $3,8 \mathrm{~m} / \mathrm{s}$, indicando uma diferença de mais de $2 \mathrm{~m} / \mathrm{s}$. Já as medianas no mesmo período oscilaram entre $1,3 \mathrm{~m} / \mathrm{s}$ e $1,5 \mathrm{~m} / \mathrm{s}$.

Ressalta-se a diferença apontada entre os períodos de 07h e 08h, em que o limite superior passou de $3,7 \mathrm{~m} / \mathrm{s}$ para $4,3 \mathrm{~m} / \mathrm{s}$, refletindo a maior diferença de uma hora para a outra.

\section{Figura 8 - Oscilação horária média dos valores de velocidade dos ventos (m/s) em Curitiba - 2004-2015}

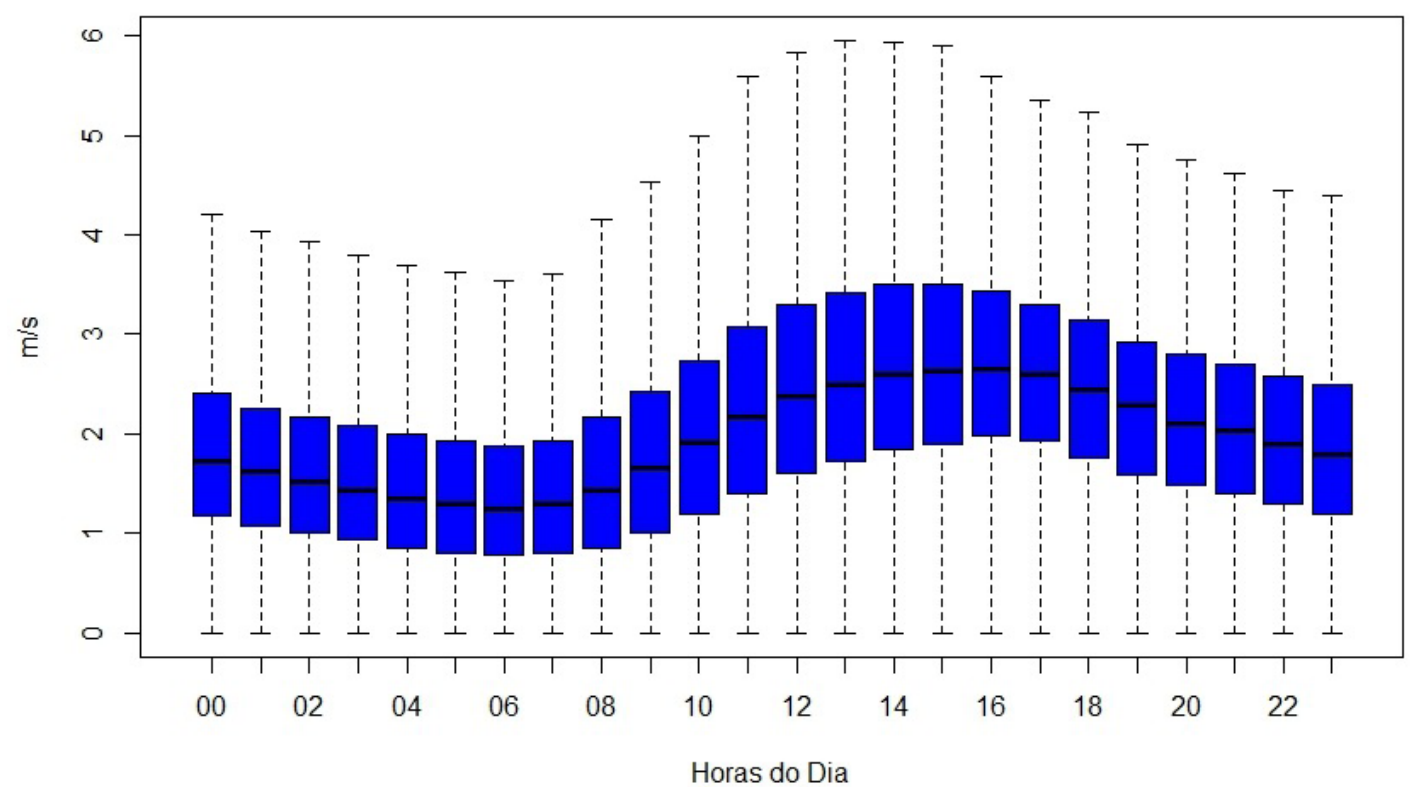

Quanto à prevalência na direção dos ventos, a Figura 9 permite vê-la ao longo de um ano. De modo geral, observa-se uma prevalência dos ventos provindos dos quadrantes leste e nordeste em todos os meses do ano na capital paranaense.

De janeiro a maio, a prevalência foi leste, com destaque para o mês de março, quando $38 \%$ da frequência de ventos foram de leste, seguidos por nordeste (20\%), enquanto os quadrantes sul e sudoeste apresentam menos de $2 \%$ do total.

Estes últimos se configuraram como os quadrantes com menor frequência de ventos, representando, de maneira combinada, menos de $5 \%$ da frequência de ventos em todos os meses. 
Durante os meses de junho a agosto, observou-se uma alternância, com maior frequência de ventos passando de leste para nordeste. No mês de julho, o quadrante nordeste representou $28 \%$ do total, contra $23 \%$ do leste. Já em agosto, os valores foram praticamente iguais, com ambos muito próximos a $29 \%$ do total.

A predominância de ventos de leste volta a partir do mês de setembro, se mantendo assim até o final do ano, com maior destaque para o mês de novembro, em que, $43 \%$ do total dos ventos provêm de leste, e 20\% de nordeste.

\section{Figura 9 - Oscilação média mensal da direção/velocidade dos ventos (m/s) em Curitiba - 2004-2015}

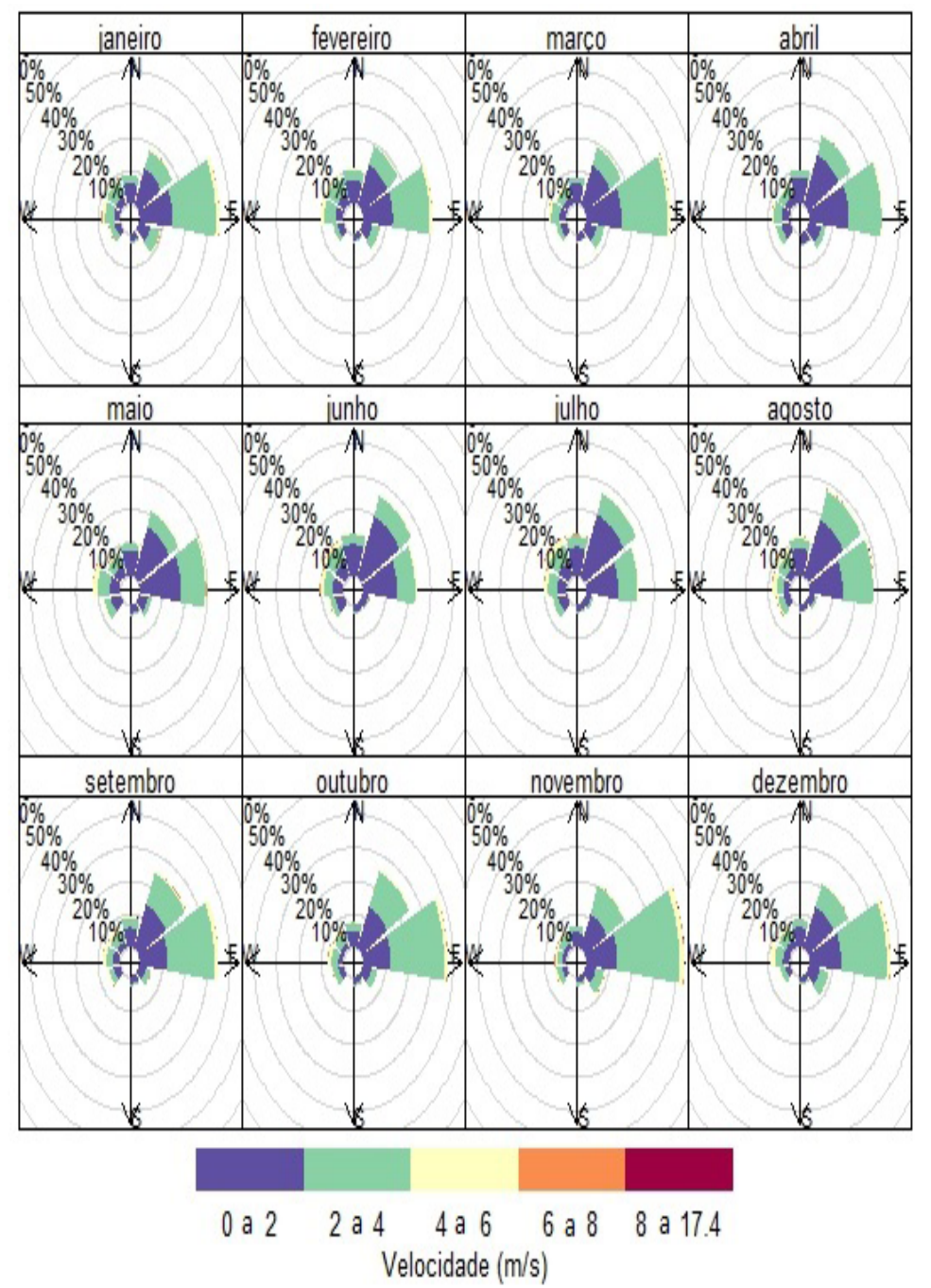

Nota-se que o percentual dos quadrantes oeste e noroeste também aumentou com o avanço do inverno. Os meses de maio, junho e julho apresentaram mais de 10\% de seu total de registros em cada um desses quadrantes.

Outro ponto que a Figura 9 mostra é a velocidade dos ventos. Percebe-se que, apesar de menor frequência, os ventos provindos dos quadrantes oeste e noroeste apresentam maior velocidade que os demais setores. Focalizando os meses de maio a setembro, percebe-se mais claramente que a maioria dos ventos com velocidade superior a $4 \mathrm{~m} / \mathrm{s}$ provém ditos quadrantes. 
Usando o mesmo tipo de gráfico para traçar um panorama horário das direções e velocidade dos ventos, nota-se que os quadrantes leste e nordeste são os predominantes ao longo do dia, com poucas variações (Figuras 10 e 11).

Nas primeiras horas do dia (Figura 10), de 00h até 02h, a frequência de ventos provindos de leste oscila entre 35\% e 40\%, seguida pelo quadrante leste, com 30\%. Depois, no mesmo horário, temos os ventos provindos de norte, que se mantiveram em $8 \%$, e os dos demais quadrantes com menos de $5 \%$.

Das $03 \mathrm{~h}$ até as $07 \mathrm{~h}$, observa-se um crescimento gradual dos ventos oriundos de nordeste, sendo que as $08 \mathrm{~h}$ já se observa este como o quadrante predominante na cidade $29 \%$ de frequência contra $28 \%$ do quadrante leste. Igualmente percebe-se um aumento gradativo nos demais quadrantes, com o setor norte representando $12 \%$ e os demais se mantendo entre $5 \%$ e $7 \%$.

\section{Figura 10 - Oscilação horária média da direção/velocidade dos ventos (m/s) em Curitiba - 00h-11h - 2004-2015}

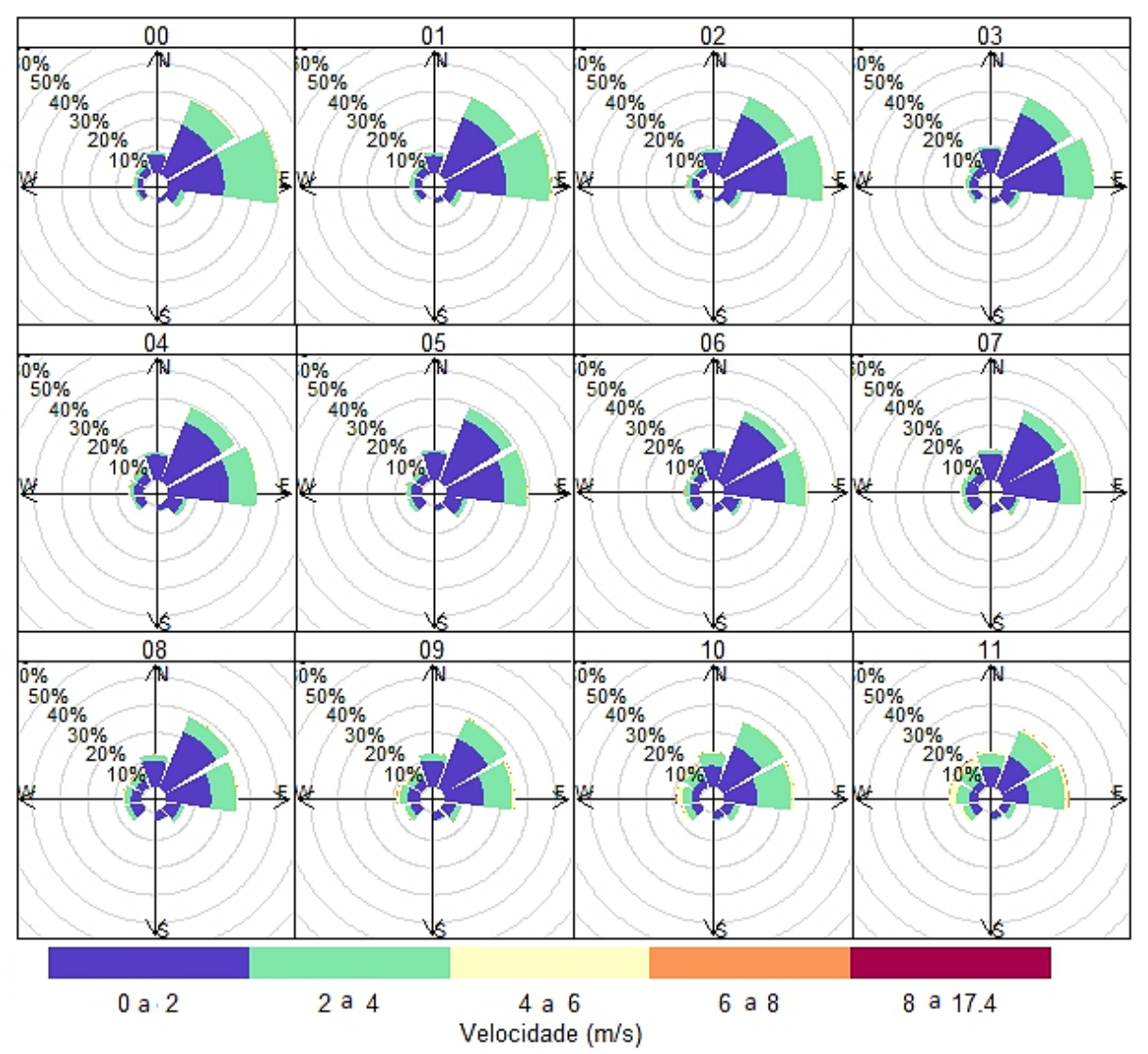

A partir das 11 h (Figura 11) o quadrante leste volta a ter predominância, mas com diferença menor para os demais. Ainda a partir deste período, passa-se a ter um crescimento gradual dos ventos provindos de oeste e noroeste, sobretudo dos com velocidade acima de $4 \mathrm{~m} / \mathrm{s}$.

No horário das $14 \mathrm{~h}$ os ventos destes últimos quadrantes citados já são mais frequentes em Curitiba que os provindos do quadrante nordeste, que vinham decaindo desde as $11 \mathrm{~h} \mathrm{e}$ assim seguem até as $18 \mathrm{~h}$, quando representam apenas 10\%. Ainda as $14 \mathrm{~h}$, a predominância do quadrante leste que se perdura até o final do dia, oscilando entre $22 \%$ da frequência, registrada nesse horário, e $44 \%$ registrados as $19 \mathrm{~h}$. 
Após as 17h, os quadrantes diferentes de leste e nordeste apresentam quedas gradativas, perdendo expressividade na dinâmica da cidade, e oscilando entre 5\% e 10\% até o final do dia.

\section{Figura 11 - Oscilação horária média da direção/velocidade dos ventos (m/s) em Curitiba - 12h-23h - 2004-2015}

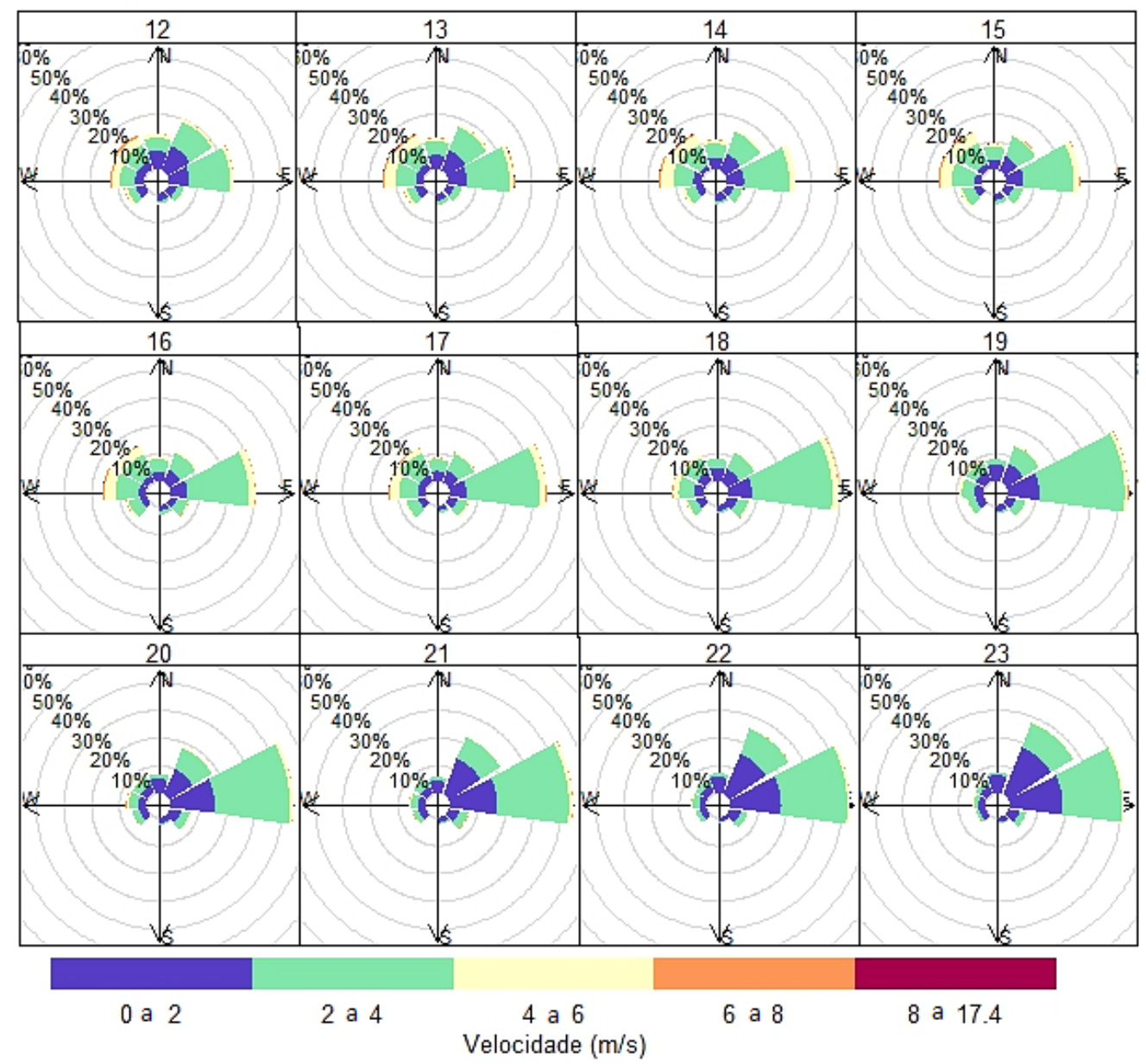

Em comparação com os estudos de Danni-Oliveira (1999), observou-se uma diferença marcante na dinâmica da direção dos ventos, com incidência maior a partir da direção nordeste.

Essa diferença pode se dever tanto às diferentes escalas temporais duas análises (diária e horária) quanto a uma possível mudança na dinâmica dos ventos nos períodos analisados.

\section{Considerações finais}

Constatou-se em Curitiba a predominância de ventos a partir do quadrante leste na maioria dos meses do ano no período da análise. Só em junho, julho e agosto predominaram mais ventos do setor nordeste do que da direção leste. $O$ quadrante com menor percentual de ventos foi o do sul, seguido do de sudoeste.

Observou-se também que, ao longo dos meses, os quadrantes oeste, noroeste e sudoeste apresentaram maior percentual de ventos a mais de $4 \mathrm{~m} / \mathrm{s}$.

Os ventos mais velozes ocorreram de setembro a janeiro, época mais quente e mais chuvosa na cidade; por outro lado, entre abril e julho, período menos chuvoso e frio, os ventos apresentaram as menores velocidades. 
O estudo de ventos em escala horária permite observar a mudança nas direções predominantes ao longo de um dia, e verificou-se que os ventos de leste não são majoritários apenas entre $04 \mathrm{~h}$ e $1 \mathrm{lh}$, quando predomina o setor nordeste.

A velocidade do vento ao longo de um dia oscila em decorrência do aporte de radiação. Observou-se que o período do dia com velocidade mais alta é entre $12 \mathrm{~h}$ e $14 \mathrm{~h}$, enquanto o de velocidade mais baixa é logo antes de o sol nascer, entre 04h e 06h.

Outra situação observada na série é o fato de que todas as vezes que os ventos ultrapassaram os $10 \mathrm{~m} / \mathrm{s}$ sua direção era noroeste, oeste ou sudoeste, portanto, provindo do mesmo quadrante.

Ressalta-se a importância de pesquisar a dinâmica dos ventos em cidades pela já mencionada gama de fatores que sofrem sua influência direta. Ademais, um maior detalhamento de sua dinâmica envolvendo estações alocadas em outros pontos da cidade poderia complementar tais conclusões, mas a falta de dados e estrutura para tal limita essas pesquisas.

\section{Referências}

ÁGUAS PARANÁ. Instituto das Águas do Paraná. Modelo Digital de Elevação (DEM) da Bacia do Alto Iguaçu. Disponível em: http://www.aguasparana.pr.gov.br/modules/conteudo/conteudo.php?conteudo=95. Acesso em: 10 abr. 2018.

ALONSO, C. D.; GODINHO, R. A evolução da qualidade do ar em Cubatão, Revista Química Nova, v. 15, n. 2, p. 115-176, 1992.

CARSLAW, D. C.; ROPKINS, K. Openair: an R package for air quality data analysis. Environmental Modelling E Software, v. 27-28, p. 52-61, 2012.

CAVIGLIONE, J. H.; KIIHL, L. R. B.; CARAMORI, P. H.; OLIVEIRA, D. Cartas climáticas do Paraná. Londrina : lapar, 2000. 1 CD.

DANNI-OLIVEIRA, I. M. Aspectos climáticos de curitiba-PR: uma contribuição para o ensino médio. Revista Ra'ega, v. 3, p. 231-254, 1999.

DANNI-OLIVEIRA, I. M.; MENDONÇA, F. Clima: noções básicas e climas do Brasil. São Paulo: Oficina de Textos, 2007.

IBGE. Instituto Brasileiro de Geografia e Estatística. Censo Demográfico 2010. Disponível em: http://www.censo2010.ibge.gov.br. Acesso em: 20 set. 2016.

INMET. Instituto Nacional de Meteorologia. Normais Climatológicas do Brasil. Disponível em: http://www.inmet.gov.br/portal/index.php?r=clima/normaisclimatologicas. Acesso em: 10 abr. 2018.

MONTEIRO, C. A. F. A dinâmica climática e as chuvas no estado de São Paulo: estudo geográfico sob a forma de Atlas. Igeop, São Paulo: IG-USP, 1973. 
MUNHOZ, F. C.; GARCIA, A. Caracterização da velocidade e direção predominante dos ventos para a localidade de Ituverava-SP. Revista Brasileira de Meteorologia, v. 23, n. 1, p. 30-34, 2008.

OLIVEIRA JÚNIOR, J. F; SOUZA, J. C. S.; DIAS, F. O.; GOIS, G.; GONÇALVES, I. F. S.; SILVA, M. S. Caracterização do regime de vento no município de Seropédica, Rio de Janeiro (2001-2010). Revista Floresta e Ambiente, v. 20, n. 4, p. 447-459, 2013. 